\title{
Technical Note: On methodologies for determining the size-normalised weight of planktic foraminifera
}

\author{
C. J. Beer ${ }^{1}$, R. Schiebel ${ }^{1, *}$, and P. A. Wilson ${ }^{1}$ \\ ${ }^{1}$ National Oceanography Centre, Southampton, University of Southampton, European Way, Southampton, SO14 3ZH, UK \\ * now at: Laboratoire d'Etude des Bio-indicateurs Actuels et Fossiles, Université d'Angers, 2 Boulevard Lavoisier, \\ Angers CEDEX, 49045, France
}

Received: 4 December 2009 - Published in Biogeosciences Discuss.: 3 February 2010

Revised: 11 June 2010 - Accepted: 13 July 2010 - Published: 16 July 2010

\begin{abstract}
The size-normalised weight (SNW) of planktic foraminifera, a measure of test wall thickness and density, is potentially a valuable palaeo-proxy for marine carbon chemistry. As increasing attention is given to developing this proxy it is important that methods are comparable between studies. Here, we compare SNW data generated using two different methods to account for variability in test size, namely (i) the narrow (50 $\mu \mathrm{m}$ range) sieve fraction method and (ii) the individually measured test size method. Using specimens from the $200-250 \mu \mathrm{m}$ sieve fraction range collected in multinet samples from the North Atlantic, we find that sieving does not constrain size sufficiently well to isolate changes in weight driven by variations in test wall thickness and density from those driven by size. We estimate that the SNW data produced as part of this study are associated with an uncertainty, or error bar, of about $\pm 11 \%$. Errors associated with the narrow sieve fraction method may be reduced by decreasing the size of the sieve window, by using larger tests and by increasing the number tests employed. In situations where numerous large tests are unavailable, however, substantial errors associated with this sieve method remain unavoidable. In such circumstances the individually measured test size method provides a better means for estimating SNW because, as our results show, this method isolates changes in weight driven by variations in test wall thickness and density from those driven by size.
\end{abstract}

\section{Introduction}

The ocean contains about $38 \mathrm{Gt}$ of carbon, accounting for $98 \%$ of the combined ocean-atmosphere carbon reservoir (Zeebe and Wolf-Gladrow, 2001). The size and nature of

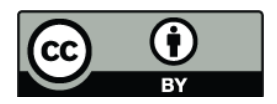

Correspondence to: C. J. Beer (cjb1@noc.soton.ac.uk) the marine carbon inventory implies that the ocean plays a significant role in determining atmospheric $p \mathrm{CO}_{2}$ concentrations, and therefore global climate, from decadal to millenial timescales (Broecker and Peng, 1982). Palaeoclimatic research has provided valuable insights into the global climate system, but our understanding of the carbon cycle is far from complete (e.g. Archer et al., 2000; Sigman and Boyle, 2000; Peacock et al., 2006). As anthropogenic $p \mathrm{CO}_{2}$ emissions continue to alter marine carbon chemistry (Caldeira and Wickett, 2003; Zeebe et al., 2008), with ill-defined consequences for marine biota (Orr et al., 2005; Raven et al., 2005), there is a pressing need to better understand the operation of marine biogeochemical processes.

One palaeo-proxy with the potential to shed light on past changes in marine carbon chemistry is the size-normalised weight (SNW) of planktic foraminifera, which is a measure of test wall thickness and density. SNW of planktic foraminifera collected from the seafloor is influenced by calcite dissolution processes, with lower SNW values indicative of waters with a low calcite saturation state $(\Omega)$ and low $\left[\mathrm{CO}_{3}^{2-}\right]$ (Zeebe and Wolf-Gladrow, 2001; Broecker and Clark, 2001a). SNW was therefore originally proposed and developed as a quantitative deepwater $\left[\mathrm{CO}_{3}^{2-}\right]$ proxy (Lohmann, 1995; Broecker and Clark, 2001a,b, 2003) under the assumption that, for any given species, the initial SNW is uniform in space and time. We now know, however, that the initial SNW is determined by the ambient environmental conditions during calcification (Broecker and Clark, 2004). In particular, culture studies reveal that calcification rate is enhanced, and the test wall thickness and hence SNW increased, at elevated $\mathrm{CO}_{3}^{2-}$ concentrations (Bijma et al., 1999, 2002; Russell et al., 2004). Well-preserved foraminiferal specimens collected from marine sediments have therefore been used to investigate past changes in surface water $\left[\mathrm{CO}_{3}^{2-}\right]$, which, significantly, is inversely related to atmospheric $p \mathrm{CO}_{2}$ concentrations (e.g. Barker and Elderfield, 2002; Moy et al., 2009; de Moel et al., 2009). However,

Published by Copernicus Publications on behalf of the European Geosciences Union. 
a recent analysis of the $\mathrm{SNW}-\left[\mathrm{CO}_{3}^{2-}\right]$ correlations suggests that SNW is a function of multiple, as yet undetermined, environmental controls and not $\left[\mathrm{CO}_{3}^{2-}\right]$ exclusively (Beer et al., 2010). Although clearly in development, SNW remains an inexpensive, easily determined and potentially highly valuable palaeo-proxy.

Different researchers have used different methods to generate SNW data, making direct comparison between studies difficult. In essence, techniques used to establish SNW attempt to gauge changes in test wall thickness/density and must remove the influence of test size on weight. It is important that size is accounted for effectively because test size can vary according to ambient environmental conditions experienced during growth (Hecht, 1976; Schmidt et al., 2002, 2006) and therefore potentially obfuscate the test wall thickness/density signal. Broadly speaking, size is constrained, and SNW established, using one of two methods. The simplest method with most rapid throughput involves weighing specimens picked from a narrow sieve fraction (typically a $50 \mu \mathrm{m}$ range) with the resultant data here termed the "sievebased weight" (SBW; e.g. Broecker and Clark, 2001a). The second method is more labour-intensive and involves measuring the size of each individual test which has been picked from within a narrow sieve fraction. The test weights are then normalised to the mean measured test size to obtain a "measurement-based weight" (MBW; e.g. Barker and Elderfield, 2002). Ideally, weight would be normalised to the mean volume enclosed within the exterior perimeter of the test wall. Test volume is, however, very difficult and timeconsuming to establish and alternative size parameters, such as test diameter, are typically substituted for volume.

In this study, well-preserved planktic foraminiferal specimens collected by nets from the water column in the North Atlantic Ocean are employed to generate SNW estimates using both techniques on the same aliquots. Our aims are to (i) quantitatively assess whether sieving satisfactorily removes the influence of size on test weight, (ii) determine which of the two techniques are preferable for the estimation of SNW and (iii) consider which of the test size measurements (e.g. diameter) is best used to normalise test weight. Note that we do not consider intra-aliquot variations in test weights as part of this study, and we do not claim to provide an infallible technique for the production of SNW data. Rather, we aim to outline a preferred approach for the generation of SNW datasets that does not demand the use of highly specialised laboratory equipment.

\section{Methods}

Foraminiferal specimens of Globigerina bulloides, Globorotalia inflata, Globigerinita glutinata and Neogloboquadrina incompta were sampled from the water column at standardised depth intervals $(0-20 \mathrm{~m}, 20-40 \mathrm{~m}, 40-60 \mathrm{~m}$, $40-60 \mathrm{~m}, \quad 60-80 \mathrm{~m}, \quad 80-100 \mathrm{~m}, 100-200 \mathrm{~m}, 200-300 \mathrm{~m}$,
300-500 m, 500-700 m, 700-1000 m, 1000-1500 m, 1500$2000 \mathrm{~m}, 2000-2500 \mathrm{~m}$ ) using a multiple opening-closing net (for additional detail on sampling procedures, refer to Schiebel et al., 1995). Formalin (4\%) was added to the samples in order to retard remineralisation of organic material, which engenders carbonate dissolution, and buffered using hexamethyltetramine to a $\mathrm{pH}$ of 8.2. If samples were stored for prolonged periods, regular $\mathrm{pH}$ measurements were carried out and additional hexamethyltetramine added if necessary to prevent degradation. Post-cruise, samples were washed over a $100 \mu \mathrm{m}$ sieve using tap water. Specimens were then isolated from the sample using a pipette and dried at room temperature in glass petri dishes before sieving. Only specimens of $G$. bulloides that did not possess spines were employed as part of this study. Specimens were delicately brush-cleaned to remove adhered material not associated with the foraminifera prior to analysis.

A total of 219 aliquots from 29 locations in the North Atlantic, mainly in the vicinity of BIOTRANS $\left(47^{\circ} \mathrm{N}, 20^{\circ} \mathrm{E}\right.$; Table 1), were used in this study. A minimum of 10 specimens $($ mean $=19)$ from the $200-250 \mu \mathrm{m}$ fraction were picked, uniformly orientated with umbilical side facing upwards and measured using an integrated, semi-automated microscope and image analysis system (cf. Bollmann et al., 2004). Images were acquired using Leica Z16 APO apochromatic monocular microscope and integrated 12 megapixel Olympus CC12 colour camera (at 5 times magnification) and processed with analySIS software (Olympus, version 5). Use of the 200-250 $\mu \mathrm{m}$ fraction represents a compromise between the need to obtain a statistically reasonable number of tests and the desire to use large specimens and thereby obtain a sufficient aliquot mass for precision weighing. The image analysis system provides mean values for the test silhouette area and test diameter for each aliquot, where diameter is taken to be the mean of the diameters which bisect the centre of the foraminiferal test, as observed in 2-D. Note that in using the term diameter, we do not imply a measure of girth, but rather a 1-D measure of test size established from 2-D images.

Following size-analysis, the tests were placed into preweighed aluminium capsules and transferred to an environmentally controlled weighing room. The samples were left for a minimum of $12 \mathrm{~h}$ to equilibrate with the ambient atmospheric moisture content before being weighed using a Satorious $M E 5$ balance (precision $=0.001 \mathrm{mg}$ ) to obtain SBW. Samples were not oven dried before being weighed because it was found that they increased in weight during the weighing process, presumably as they absorbed moisture from the atmosphere. MBW was calculated by normalising SBW to the mean diameter $\left(\mathrm{MBW}_{\text {diam }}\right)$ and area $\left(\mathrm{MBW}_{\text {area }}\right)$ for the corresponding species. We note that, like the majority of researchers who generate SNW data, we do not have the means to assess test volume. We are therefore unable to test directly as part of this study the influence of substitution of test diameter or area for volume. While the adequacy of this 
Table 1. Locations of multinet sampling stations in the North Atlantic.

\begin{tabular}{lccc}
\hline Cruise & Station & Latitude $\left({ }^{\circ} \mathrm{N}\right)$ & Longitude $\left({ }^{\circ} \mathrm{W}\right)$ \\
\hline M21-1 & 80 & 47.01 & 19.29 \\
M21-1 & 87 & 47.13 & 19.34 \\
M21-1 & 92 & 47.28 & 19.72 \\
M21-1 & 96 & 47.27 & 19.52 \\
M21-1 & 99 & 47.30 & 19.51 \\
M21-1 & 102 & 47.29 & 19.52 \\
M21-1 & 111 & 47.48 & 19.13 \\
M21-2 & 148 & 47.68 & 19.82 \\
M21-2 & 158 & 47.28 & 19.07 \\
M21-2 & 164 & 47.40 & 18.88 \\
M21-2 & 167 & 47.33 & 18.55 \\
M21-2 & 172 & 47.18 & 19.56 \\
M21-2 & 176 & 47.08 & 18.57 \\
M21-2 & 177 & 47.03 & 18.58 \\
M21-3 & 204 & 47.74 & 19.70 \\
M21-3 & 211 & 47.62 & 19.49 \\
M21-3 & 214 & 52.50 & 20.00 \\
M21-3 & 216 & 54.65 & 22.45 \\
M21-3 & 217 & 54.77 & 20.73 \\
M21-3 & 219 & 57.50 & 19.99 \\
M21-3 & 223 & 59.30 & 19.70 \\
M36-5 & 331 & 47.18 & 19.57 \\
M36-5 & 354 & 47.60 & 22.38 \\
M36-5 & 358 & 47.09 & 17.45 \\
M12-3 & 367 & 47.16 & 19.32 \\
M12-3 & 374 & 47.16 & 19.34 \\
M12-3 & 381 & 47.26 & 18.49 \\
M36-6 & 390 & 47.18 & 19.55 \\
M26-1 & 455 & 47.47 & 19.53 \\
\hline
\end{tabular}

substitution clearly needs to be validated, such an examination goes beyond the scope of this study, which is simply to compare two often-employed techniques for the generation of SNW datasets.

Given the large density difference between calcite $\left(2.71 \mathrm{~g} \mathrm{~cm}^{-3}\right)$ and wet cytoplasm $\left(1.07 \mathrm{~g} \mathrm{~cm}^{-3}\right)$, and their fractional contributions to the dry test mass $(0.97$ and 0.03 , respectively; Schiebel et al., 2007) we did not treat the specimens for organic matter prior to weighing.

\section{Results}

In Fig. 1 we show SBW against test size (area) for all four species considered in this study - in each case our data reveal a correlation between SBW and area $\left(0.5<r^{2}<0.7\right)$. In contrast, no such correlations are obtained between $\mathrm{MBW}_{\text {area }}$ and area (Fig. 2). Note that the weight differences observed within our dataset are quite large, and are perhaps attributable to gametogenic crusts or other secondary calcite. Our data also demonstrate that SBW correlates more strongly with

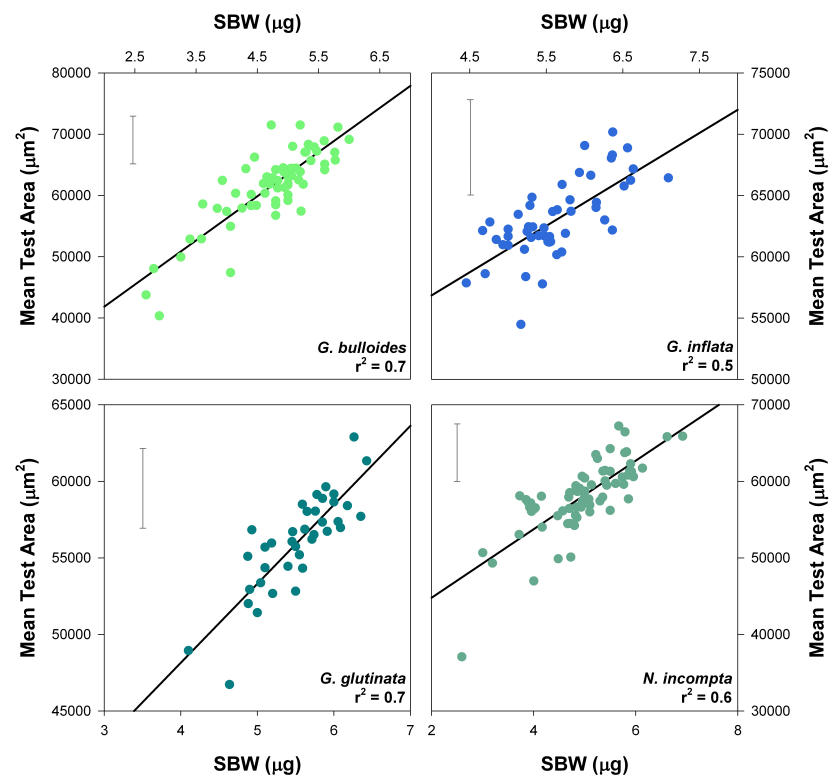

Fig. 1. The mean sieve-based test weight (SBW; $\mu \mathrm{g}$ ) versus the mean test area $\left(\mu \mathrm{m}^{2}\right)$ for aliquots of planktic foraminifera sampled using a multiple-opening-closing net in the North Atlantic Ocean picked from the $200-250 \mu \mathrm{m}$ sieve fraction. The correlations observed $\left(0.5<r^{2}<0.7 ; p<0.0001\right)$ suggest that typically "narrow" sieve fractions provide an insufficient control on the sizedetermined variations in test weight.

$\operatorname{MBW}_{\text {diam }}\left(r^{2}=0.91 ; p<0.0001\right)$ than $\mathrm{MBW}_{\text {area }}\left(r^{2}=0.67\right.$; $p<0.0001$; supplementary Fig. 1 , see supplemental material). In Fig. 3 we show the percentage difference between $\mathrm{MBW}_{\text {area }}$ and SBW for each aliquot. Our results show that the mean difference between $\mathrm{MBW}_{\text {area }}$ and $\mathrm{SBW}$ is close to zero, but the standard deviation is $11.3 \%$. Overall, $23 \%$ of $\mathrm{MBW}_{\text {area }}$ values differ from their corresponding SBW values by more than $\pm 10 \%$.

\section{Discussion}

\subsection{Efficacy of sieving}

The correlations between SBW and area seen in our data $\left(0.5<r^{2}<0.7\right.$; Fig. 1) indicate that use of a narrow sieve fraction $(200-250 \mu \mathrm{m})$ fails to remove the influence of test size on test weight. These correlations exist despite the environmental influences on test weight that act to obscure such correlations by increasing inter-aliquot weight (and size) variability. Similarly, the presence of gametogenic calcite, which is an inherently variable feature in our dataset because we use specimens collected from throughout the water column, does not obliterate the correlations between test area and SBW that we observe. This underlines the observation that use of a narrow sieve fraction fails to remove the influence of test size on test weight, at least for the sieve fraction employed in 

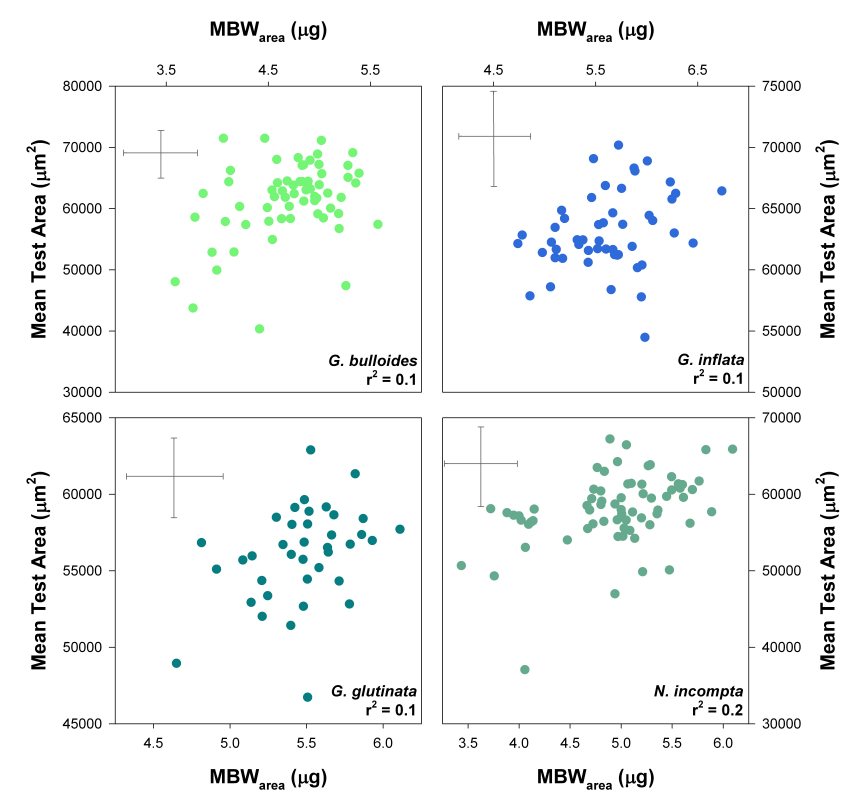

Fig. 2. Measurement-based weight $\left(\mathrm{MBW}_{\text {area }} \mu \mathrm{gg}\right)$ versus test area $\left(\mu \mathrm{m}^{2}\right)$ for each of the species considered as part of this study. No correlations are observed between $\mathrm{MBW}_{\text {area }}$ and area, suggesting that the measurement-based method isolates the influence of test wall thickness and density from that of size on test weight.

this study $(200-250 \mu \mathrm{m})$. The maximum effect of size variations within the sieve fraction can be calculated by assuming that all the foraminifera weighed in an aliquot are either $200 \mu \mathrm{m}$ or $250 \mu \mathrm{m}$ in diameter, spherical in shape and effectively sieved. If all specimens were $200 \mu \mathrm{m}$ in diameter, and normalised to the mid-point of the range $(225 \mu \mathrm{m})$, SBW would be $27 \%$ less than $\mathrm{MBW}_{\text {area }}$. Conversely, if all specimens were $250 \mu \mathrm{m}$ in diameter, SBW would exceed $\mathrm{MBW}_{\text {area }}$ by $19 \%$. However, because foraminiferal tests are not spherical, some tests are found outside of these theoretical extremes (Fig. 3). Moreover, we find that sieved tests are larger than would be expected given the sieve fraction used $(200-250 \mu \mathrm{m})$, with the mean test diameter all of specimens employed in this study being ca. $300 \mu \mathrm{m}$ (refer to supplementary Fig. 2 and supplementary Table 1, see supplemental material). Combined, these data reveal the inadequacy of using the $200-250 \mu \mathrm{m}$ sieve fraction to constrain size variations, and hence characterise variations in test wall thickness and density.

The finding that SBWs are in part determined by test size implies that SBW is not a good approximation of SNW. The mean difference between values of SBW and $\mathrm{MBW}_{\text {area }}$ is approximately zero, but the standard deviation $(\sigma)$ is $11.3 \%$. We take this value (11\%) to equal the error in SBW for the sieve fraction used in this study $(200-250 \mu \mathrm{m})$. Although not directly comparable because different studies use different sieve size fractions, it is instructive to note that this error estimate is of the same order of magnitude as the change

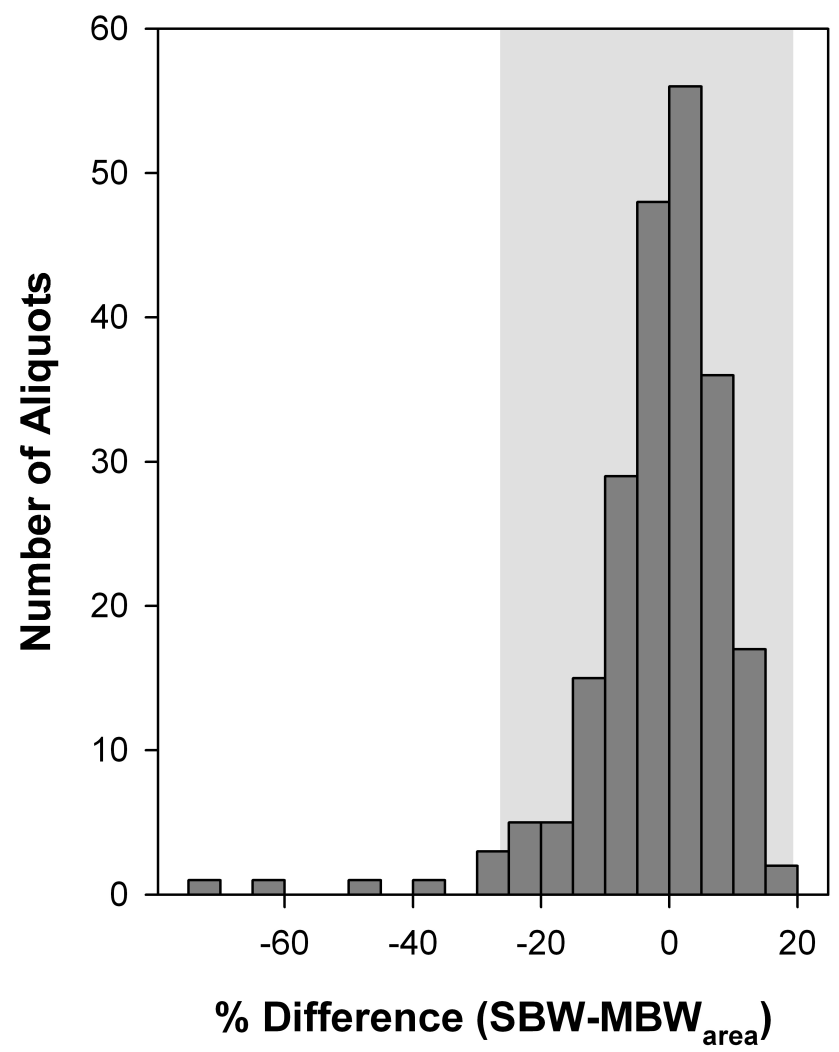

Fig. 3. The difference between "sieve-based weight" (SBW) and area-normalised weight $\left(\mathrm{MBW}_{\text {area }}\right)$. The grey shaded area represents the theoretical extreme differences, assuming that the specimens are effectively sieved and spherical (refer to text).

observed in some published downcore records of SNW. For example, published records describe a $20-33 \%$ change in SNW during the last deglaciation (Barker and Elderfield, 2002; de Moel et al., 2009; Moy et al., 2009), a 25\% change attributed to ocean acidification (de Moel et al., 2009) and a $5-20 \%$ change in SNW of foraminifera cultured over a $\left[\mathrm{CO}_{3}^{2-}\right]$ range of $300-200 \mu \mathrm{mol} \mathrm{kg}{ }^{-1}$ (Bijma et al., 1999, 2002).

The use of larger specimens and a narrower sieve size window improves sieve-based estimates of SNW, as does increasing the number of specimens employed (J. Bijma, personal communication, 2010). We are unable to examine this method of improvement through explicit measurements because the sample suite used as part of this study does not contain sufficient numbers of large foraminifera. Instead, we calculate the potential difference between SBW and $\mathrm{MBW}_{\text {area }}$ and thereby illustrate that the potential difference decreases with the use of larger specimens and a narrower sieve fraction window (Fig. 4). However, reducing the size of the sieve size window reduces the number of specimens available for weighing, as does use of large specimens. Moreover, there are important pragmatic considerations. SNW data are often generated as a "by-product" on samples prepared for 


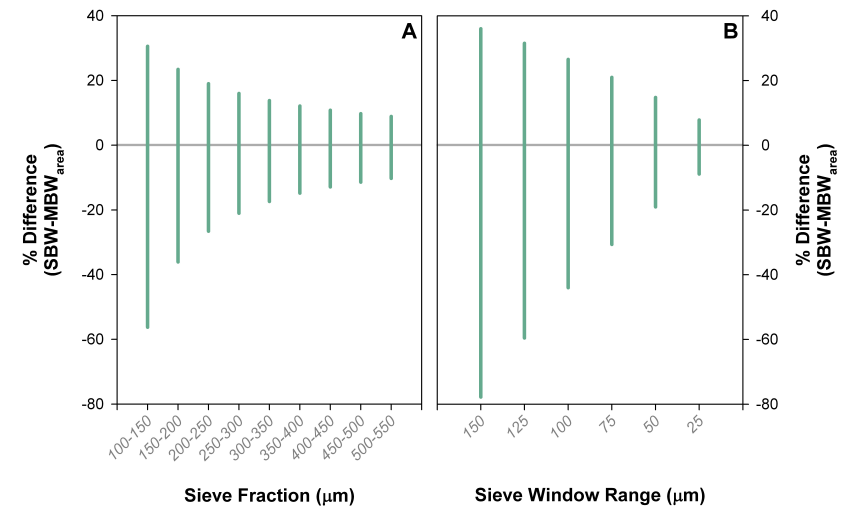

Fig. 4. (A) The theoretical minimum and maximum percentage difference between SBW and $\mathrm{MBW}_{\text {area }}$ calculated for foraminiferal tests of different sizes sieved using a $50 \mu \mathrm{m}$ window. $\mathrm{MBW}_{\text {area }}$ is calculated to the midpoint of the size range and tests are assumed to be spherical. The extreme values are determined by assuming all the tests within an aliquot lie at the extreme end of the size range. (B) The difference between SBW and $\mathrm{MBW}_{\text {area }}$ for different sieve window sizes from 150 to $25 \mu \mathrm{m}$ centred on $300 \mu \mathrm{m}$. The smallest differences between SBW and $\mathrm{MBW}_{\text {area }}$ are obtained by using large foraminifera and a small sieve window.

geochemical analyses, so the sieve size fraction may be predetermined. Hence, while the SBW method is best suited to situations where a large number of large specimens are available from a narrow sieve fraction, in many circumstances, an alternative approach to generating SNW is needed. Indeed, the sample suite used as part of this study precludes the use of a large number of large specimens to generate SNW data and, therefore, necessitates the use of an alternative to the sieve-based method for the establishment of SNW values.

\subsection{Establishing MBW}

Ideally, measurement-based weight is calculated by normalizing SBW to test volume. However, volume is very difficult to measure so must be either estimated from, or substituted by, alternative parameter(s). In the absence of empirical functions linking test volume to more easily measured variables, volume must be estimated by assuming that the foraminiferal test is a certain shape. An alternative approach, which avoids the use of necessarily crude approximations of the test shape, is the use of area or diameter to directly normalise test weight. In doing so, test diameter, area and volume are assumed to remain proportional to one another over the size range of interest (Barker, 2002). Although proportionality cannot be demonstrated (because of the absence of volume measurements) the strong correlation between area and diameter $\left(r^{2}=0.87\right)$ lends support to the assumption of proportionality between the three measurements. Moreover, our results indicate that, unlike SBW, both $\mathrm{MBW}_{\text {diam }}$ and $\mathrm{MBW}_{\text {area }}$ do not correlate with test area $\left(r^{2}=0.18\right.$ and $r^{2}=0.007$, respectively; supplementary Fig. 3;
Fig. 2) and diameter $\left(r^{2}=0.07\right.$ and $r^{2}=0.003$, respectively; supplementary Fig. 3). This finding suggests that MBW, calculated using either area or diameter, provides a means by which variations in test wall density and thickness can be reliably characterised.

\section{Conclusions}

The SNW of planktic foraminifera, a measure of test wall thickness and density, has the potential to provide valuable palaeoceanographic information. However, the different methods employed by different workers to establish SNW makes comparisons between studies difficult. Our results, based on specimens picked from the $200-250 \mu \mathrm{m}$ fraction, show that sieving the tests does not adequately remove the influence of test size. In our experiment, SNW estimates based on the sieve-based method using tests from the 200$250 \mu \mathrm{m}$ fraction are associated with an error of ca. $11 \%$. This source of error may be reduced by increasing the number of specimens per aliquot and by employing a smaller sieve fraction range relative to the size of the foraminifera examined. However, in many circumstances this will not be practically possible because, for example, too few large tests are present. In such circumstances it is preferable to employ the measurement-based method, which does not necessitate the use of numerous large specimens picked from a very narrow sieve size window, in order to characterise test wall thickness and density and thereby obtain reliable SNW estimates.

\section{Supplementary material related to this article is available online at: http://www.biogeosciences.net/7/2193/2010/ bg-7-2193-2010-supplement.pdf.}

Acknowledgements. We would like to thank the reviewers for their insightful and helpful comments, which helped to improve this contribution. We in particular thank Jelle Bijma for his generous offer of data and informative review.

Edited by: H. Kitazato

\section{References}

Archer, D., Winguth, A., Lea, D., and Mahowald, N.: What caused the glacial/interglacial atmospheric $p \mathrm{CO}_{2}$ cycles?, Rev. Geophys., 38(2), 159-189, 2000.

Barker, S.: Planktic foraminiferal proxies for temperature and $\mathrm{CO}_{2}$, Ph.D. thesis, University of Cambridge, 2002.

Barker, S. and Elderfield, H.: Foraminiferal calcification response to glacial-interglacial changes in atmospheric $\mathrm{CO}_{2}$, Science, 297(5582), 833-836, 2002.

Beer, C. J., Schiebel, R., and Wilson, P. A.: Examination of planktic foraminiferal test weight as a surface water $\left[\mathrm{CO}_{2}^{-3}\right]$ proxy, Geology, 38(2), 103-106, 2010. 
Bijma, J., Spero, H., and Lea, D.: Reassessing foraminiferal stable isotope geochemistry: Imapct of the ocean carbonate system (experimental results), in: Uses of Proxies in Paleoceanography: Examples from the South Atlantic, edited by: Fischer, G. and Wefer, G., Springer-Verlag, Berlin, Heidelberg, 489-512, 1999.

Bijma, J., Hönisch, B., and Zeebe, R. E.: Impact of the ocean carbonate chemistry on living foraminiferal shell weight: Comment on "Carbonate ion concentration in glacial-age deep waters of the Caribbean Sea", edited by: Broecker, W. S. and Clark, E., Geochem. Geophy. Geosy., 3(11), 1064, doi:10.1029/2002GC000388, 2002.

Bollmann, J., Quinn, P. S., Vela, M., Brabec, B., Brechner, S., Cortés, M. Y., Hilbrecht, H., Schmidt, D. N., Schiebel, R., and Thierstein, H. R.: Automated particle analysis: Calcareous microfossils, in: Image Analysis, Sediments and Paleoenvironments, edited by: Francus, P., Kluwer Academic Publishers, Dodrecht, 229-252, 2004.

Broecker, W. and Peng, T.: Tracers in the Sea, Eldigo Press, New York, 1982.

Broecker, W. S. and Clark, E.: An evaluation of Lohmann's foraminifera weight dissolution index, Paleoceanography, 16(5), 431-434, 2001a.

Broecker, W. S. and Clark, E.: Reevaluation of the $\mathrm{CaCO}_{3}$ size index paleocarbonate ion proxy, Paleoceanography, 16(6), 669671, 2001b.

Broecker, W. S. and Clark, E.: $\mathrm{CaCO}_{3}$ dissolution in the deep sea: paced by insolation cycles, Geochem. Geophy. Geosy., 4(7), 1059, doi:10.1029/2002GC000450, 2003.

Broecker, W. S. and Clark, E.: Shell weights from the South Atlantic, Geochem. Geophy. Geosy., 5(3), Q03003, doi:10.1029/2003GC000625, 2004.

Caldeira, K. and Wickett, M. E.: Oceanography: Anthropogenic carbon and ocean $\mathrm{pH}$, Nature, 425(6956), 365-365, doi:10.1038/425365a 10.1038/425365a, 2003.

de Moel, H., Ganssen, G. M., Peeters, F. J. C., Jung, S. J. A., Kroon, D., Brummer, G. J. A., and Zeebe, R. E.: Planktic foraminiferal shell thinning in the Arabian Sea due to anthropogenic ocean acidification?, Biogeosciences, 6, 1917-1925, doi:10.5194/bg-61917-2009, 2009.

Hecht, A. D.: An ecological model for test size variation in recent planktonic foraminifera: applications to the fossil record, J. Foramin. Res., 6(4), 295-311, 1976.

Lohmann, G. P.: A model for variation in the chemistry of planktonic-foraminifera due to secondary calcification and selective dissolution, Paleoceanography, 10(3), 445-457, 1995.
Moy, A. D., Howard, W. R., Bray, S. G., and Trull, T. W.: Reduced calcification in modern Southern Ocean planktonic foraminifera, Nat. Geosci., 2(4), 276-280, doi:10.1038/ngeo460, 2009.

Orr, J. C., Fabry, V. J., Aumont, O., Bopp, L., Doney, S. C., Feely, R. A., Gnanadesikan, A., Gruber, N., Ishida, A., Joos, F., Key, R. M., Lindsay, K., Maier-Reimer, E., Matear, R., Monfray, P., Mouchet, A., Najjar, R. G., Plattner, G. K., Rodgers, K. B., Sabine, C. L., Sarmiento, J. L., Schlitzer, R., Slater, R. D., Totterdell, I. J., Weirig, M. F., Yamanaka, Y., and Yool, A.: Anthropogenic ocean acidification over the twenty-first century and its impact on calcifying organisms, Nature, 437(7059), 681-686, 2005.

Peacock, S., Lane, E., and Restrepo, J. M.: A possible sequence of events for the generalized glacial-interglacial cycle, Global Biogeochem. Cy., 20(2), GB2010, doi:10.1029/2005GB002448, 2006.

Raven, J., Caldeira, K., Elderfield, H., Hoegh-Guldberg, O., Liss, P., Riebesell, U., Shepherd, J., Turley, C., and Watson, A.: Acidification due to increasing carbon dioxide, Tech. rep., The Royal Society, 2005.

Russell, A. D., Hönisch, B., Spero, H. J., and Lea, D. W.: Effects of seawater carbonate ion concentration and temperature on shell $\mathrm{U}, \mathrm{Mg}$, and $\mathrm{Sr}$ in cultured planktonic foraminifera, Geochim. Cosmochim. Ac., 68(21), 4347-4361, doi:10.1016/j.gca.2004.03.013, 2004.

Schiebel, R., B. Hiller, and C. Hemleben: Impacts of storms on recent planktic foraminiferal test production and $\mathrm{CaCO}_{3}$ flux in the North Atlantic at 47 degrees N, 20 degrees W (JGOFS), Mar. Micropaleontol., 26(1-4), 115-129, 1995.

Schiebel, R., Barker, S., Lendt, R., Thomas, H., and Bollmann, J.: Planktic foraminiferal dissolution in the twilight zone, Deep Sea Res. Pt. II, 54, 670-686, 2007.

Schmidt, D., Renaud, S., Bollmann, J., and Thierstein, H.: Environmental dependence of size in planktic foraminifers, Geochim. Cosmochim. Ac., 66(15A), A680-A680, suppl. 1, 2002.

Schmidt, D. N., Lazarus, D., Young, J. R., and Kucera, M.: Biogeography and evolution of body size in marine plankton, EarthSci. Rev., 78(3-4), 239-266, 2006.

Sigman, D. M. and Boyle, E. A.: Glacial/interglacial variations in atmospheric carbon dioxide, Nature, 407(6806), 859-869, 2000.

Zeebe, R. and Wolf-Gladrow, D.: $\mathrm{CO}_{2}$ in Seawater: Equilibrium, Kinetics, Isotopes, Elsevier Oceanography Series, vol. 65, Elsevier, 2001.

Zeebe, R. E., Zachos, J. C., Caldeira, K., and Tyrrell, T.: Oceans: Carbon emissions and acidification, Science, 321(5885), 51-52, 2008. 